\title{
The Spontaneously Hypertensive Rat (8)
}

\section{Proceedings of VIII Annual Scientific Meeting of the Council for the Spontaneously Hypertensive Rat \\ October 8, 1972, Nagasaki}

Symposium : Metabolism and Hormones in the Spontaneously Hypertensive Rat

Electrolytes and Hypertension

Tetsuya INATOME, Yutaka FURUTA and Susumu YORIFUJI

(Department of Internal Medicine, Kobe University, School of Medicine, Division-1, Kobe ; and Department of Internal Medicine, Hyogo Collge of Medicine, Nishinomiya)

Electrolyte Metabolism in Substrains of Spontaneously Hypertensive Rats

Akinobu NAGAOKA, Hisashi IWATSUKA, Ziro SUZUOKI and Kozo OKAMOTO

(Biological Research Laboratories, Gentral Research Division, Takeda Chemical Industries, Ltd., Osaka; and Department of Pathology, Faculty of Medicine, Kyoto University, Kyoto)

General Survey of Glucose and Lipid Metabolism in Spontaneously Hypertensive Rats

Kiro SHIMAMOTO, Akio TERAOKA, Hisashi IWATSUKA and Ziro SUZUOKI

(Biological Research Laboratories, Gentral Research Division, Takeda Chemical Industries, Ltd., Osaka)

Electron Microscopic Study of Adrenal Cortex in Spontaneously Hypertensive Rat Kioko KAWAI, Hideo TSUCHIYAMA and Hajime SUGIHARA

(Department of Pathology, Faculty of Medicine, Nagasaki University, Nagasaki)

Metabolism of Adrenal Corticosteroids in Spontaneously Hypertensive Rats

Yukio YAMORI, Akira OOSHIMA and Kozo OKAMOTO

(Department of Pathology, Faculty of Medicine, Kyoto University, Kyoto)

Free Communications :

Effect of Sodium Intake and Angiotensin Administration on Renal Renin Content and Blood Pressure in Spontaneously Hypertensive Rats

Yasuyuki MOROTOMI, Kenjiro TANAKA and Teruo OMAE

(Second Department of Internal Medicine, Faculty of Medicine, Kyushu University, Fukuoka)

Received for publication February 1, 1973. 
Plasma Renin Activity in the Spontaneously Hypertensive Rat of Early Hypertensive Stage

Kumiko SHIONO and Hirofumi SOKABE

(Department of Pharmacology, Toho University School of Medicine, Tokyo)

The Influence of Stressful Environmental Stimuli on Changes of Catecholamines and Blood Pressure

Nagao KAJIWARA, Yoshiko KOBAYASHI, Akira MURAKAMI, Jun HASHIDA, Takahisa UCHIYAMA, Takashi KITA, Masahiko SATO, Yoshihide OKUMURA, Masashi ONO, Takeshi MIKAMI and Kenzo OSHIMA

(Department of Cardiovasology, Surugadai Nihon University Hospital, Tokyo)

Catecholamine Content and Metabolism in the Spontaneously Hypertensive Rats Masayori OZAKI

(Department of Pharmacology, Nagoya City University Medical School, Nagoya)

The Histopathological Study on the Cerebral Lesion of Spontaneously Hypertensive Rat in the Dietary Experiment

Yoshikiyo KUDO, Hiroshi KUMAGAI, Akira SASAKI and Yutaka UMEHARA (Department of Pathology, Institute of Cerebrovascular Diesease, Hirosaki University School of Medicine, Hirosaki)

Vascular Changes in the Various Substrains of Spontaneously Hypertensive Rats, Untreated and Treated with Sodium Chloride in Diet

Fumitada HAZAMA, Akira OOSHIMA, Kazuhiko TOMIMOTO and Kozo OKAMOTO

(Department of Pathology, Faculty of Medicine, Kyoto University, Kyoto)

Cardiac Hypertrophy in Spontaneously Hypertensive Rats (Further Study)

Hitoshi TANIJIRI, Masakazu IKEDA, Chujiro KASHII and Tadasu TAKATSU

(The Third Division, Department of Internal Medicine, Osaka Medical College, Takatsuki)

Hypertension Persisted Following Bilateral Adrenal Medullectomy

Kyuzo AOKI, Kazuhiro TAZUMJ, Iwao SATO, Yoshimi KOBAYASHI, Kiyoharu TAKIKAWA and Ken HOTTA

(Departments of Medicine and Physiology, School of Medicine, Nagoya City University, Nagoya)

Fundus Findings of Spontaneously Hypertensive Rats-A Study with a Scanning Electron Microscope

Kimiho IRINODA and Shigeki TAKAHASHI

(Department of Ophthalmology, Hirosaki University School of Medicine, Hirosaki)

Appendix:

Spontaneously Hypertensive Rats (SHR): An Animal Model for Hypertension Research

Kozo OKAMOTO, President of the Council 